\title{
THREE-DIMENSIONAL ANALYSIS ON STRENGTH AND DEFORMATION OF CONCRETE CONFINED BY LATERAL REINFORCEMENT
}

\author{
Paulus IRAWAN* and Koichi MAEKAWA**
}

\begin{abstract}
The three-dimensional finite element analysis of concrete columns laterally confined by steel ties and hoops is conducted. The strength gain is numerically investigated in using the elasto-plastic and fracture model for concrete. The uniformity of the confinement stress and the damage induced are enlightened in consideration of the confinement efficiency by the discretely distributed lateral steel ties and hoops. The sectional averaged lateral stress in concrete, the minimum of which along the axis of columns governs the capacity of the entire confined columns, is found to be affected by the volumetric averaged lateral stress of concrete as well as the spacing of the tie associated with the uniformity of stress states. The authors demonstrate that the spacing of lateral ties also influences the volumetric averaged confinement of concrete, which mathematically corresponds to the axial mean value of the sectional averaged confinement stress.
\end{abstract}

Key Words : confinement, finite element analysis, constitutive law, ductility

\section{INTRODUCTION}

Numerous studies of the compressive strength and deformation of core concrete confined by lateral reinforcement have already been conducted in the past from the view point of improving the seismic performance of reinforced concrete members ${ }^{1)-8)}$. In general, almost all studies were attempted on the line of experimental investigation alone. Some of the empirical design equations based on these experiments were propose ${ }^{14) \sim 19)}$ but are not explicitly used in codes of practice but paraphrased in the commentary.

The arrangement of the lateral reinforcement around confined concrete in previous investigations was similar to those actually used in engineering practice. While this approach has obvious advantage of permitting test results to be applied directly to the prediction of the behavior of actual confined structural concrete, it may mislead the effect of some influencing parameters to its behaviors. It is also clear that the applicability of the design equations derived from the experiments is limited. Besides that, no rational and mechanical backgrounds were given in the past to explain the microscopic mechanism which happens inside the concrete in the level of local nonlinearity.

The objective of this research is to analytically investigate the influence of lateral reinforcement on the strength and deformation of confined concrete. The authors have already reported the

* Graduate Student, Ms. Eng., Department of Civil Engineering, The University of Tokyo (7-3-1, Hongo, Bunkyo-ku, Tokyo 113).

** Member of JSCE, Dr. Eng., Associate Professor, Structural Division of Engineering Research Institute, The University of Tokyo (7-3-1, Hongo, Bunkyo-ku, Tokyo 113). confinement efficiency ${ }^{4}$ by continuous steel casing, where the stress induced damage over the section was the point of discussion, and the stress distribution along the axis of members was assumed to be uniform. The emphasis of this paper is placed on the non-uniform distribution of the stress and the damage along the axis of members. The core concrete confined not by steel casing but by the steel ties arranged discretely is targeted. Therefore, the ratio of the spacing to the size of the concrete core section is a key parameter.

For this purpose, an elasto-plastic and fracture constitutive model of three-dimensional finite element analysis ${ }^{10)}$ 12) is employed. A comparison between results of the three-dimensional finite element analysis and existing proposed design equations is made. Discussion on analytical results is expected to enlighten the mechanism of confinement especially related to the stress distribution along the axis of confined columns, subjected to the axial compression.

\section{FULL 3-DIMENSIONAL FINITE ELEMENT ANALYSIS}

The confinement produced by the lateral reinforcement on the core concrete creates a complex triaxial state of compression. Three-dimensional finite element analysis was applied to laterally confined concrete columns in order to take into account this effect. An elasto-plastic and fracture model $^{10) \sim 12)}$ which can evaluate the internal damage and the plasticity of damaged continuum under three-dimensional stress states was adopted. We introduced the material state variables indicating the induced damage $K$ and the plasticity $J_{2 p}$ in the constitutive laws as, 

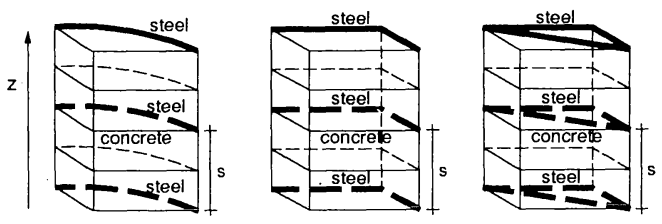

Laterally Tied Columns
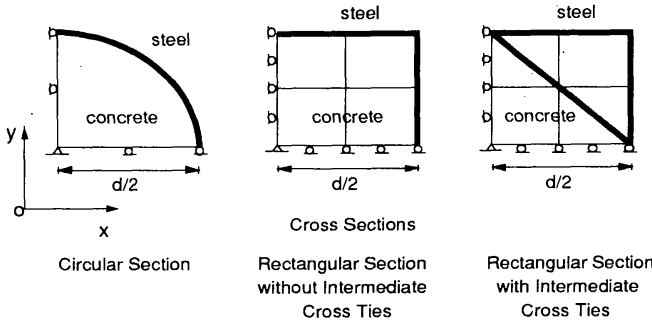

Fig.1 Discretization of Model (1/4 Model) and Definition of Referential Size ' $d$ '

$$
\begin{gathered}
K=\frac{J_{2}}{2 G_{0} J_{2 e}} \cdots \ldots . . . . \\
J_{2 p}=\int \frac{\partial J_{2 e}}{\partial \varepsilon_{e i j}} d \varepsilon_{p i j}
\end{gathered}
$$

where $J_{2}$ and $J_{2 e}$ are the second invariants of total stress and total elastic strain, and $G_{0}$ is defined as the initial elastic shear modulus. Notations $\varepsilon_{e i j}$ and $\varepsilon_{p i j}$ mean elastic and plastic strain tensors, respectively. The value of $K$ expresses the shear mode degradation of elasticity caused by the microcracks and defects ${ }^{10)}$. The value of $J_{2 p}$ is an indicator of the accumulated plasticity in the shear mode of damaged continuum ${ }^{11}$. Those state variables are spatially predicted simultaneously with the local strain and stresses under the three-dimensional confinement condition ${ }^{4}$.

A solid isoparametric element consisting of 20 nodes and a three-dimensional truss element were used for representing concrete and lateral reinforcement, respectively. The second order of Gaussian integration was specified. Symmetric geometry was considered in the discretization of the finite elements. One-fourth of the concrete section was represented by the elements in the lateral direction as shown in Fig.1. A quadrant solid element in a section was used to represent concrete of circular section in consideration of the uniform lateral stress. Since the confinement action is not uniform within the section, four elements were used to obtain more accurate results for the square one. In the longitudinal direction, two elements was allocated to represent the nonuniform distribution of the stress along the member axis. The three-dimensional truss elements without any flexural and torsional stiffness were assigned as reinforcing bars and placed along the concrete nodes. An elasto-plastic hardening model was

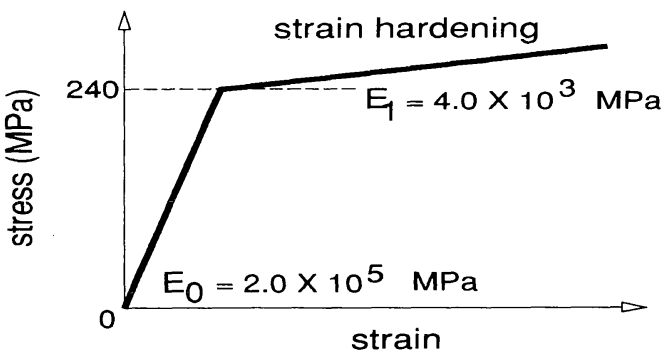

Fig.2 Elasto-plastic Hardening Model for Lateral Reinforcement (Standard)

assumed for lateral reinforcing bars as shown in Fig.2.

The loading was applied as an axial enforced displacement at the top surface of the concrete with the fixed boundary condition at the bottom surface. The displacement increment was taken considerably small. It was one-ten-thousandth of the height of the model, i.e., 100 micro strain as average axial strain increment. It should be noted that reinforcement which was represented by the truss element does not have the capability to resist the axial load, because it was placed in the lateral direction. Only the confined concrete bears the axial load and the steel reinforcement produces the confinement actions due to expansion of concrete.

The flexural rigidity was not taken into account through the truss element used in the analysis. It mechanically implies that the interacting force from steel is transferred to confined concrete only through the corners of square sections. This mode of confinement named 'corner action' may hold in the case where smaller diameter bars are used. But, arranging larger diameter bars around comparatively smaller sections of concrete, we have the additional mode of confinement as well as corner action. Actually, the line load directly applied to confined concrete is created by the steel bars having flexural rigidity as well. The effect of flexure on the confinement efficiency will be discussed in future based on the investigation of this paper.

The longitudinal reinforcement can serve to confine the concrete as well as to carry the axial force with the core concrete. In this study, the authors eliminate the longitudinal reinforcement in the analysis to purely enlighten the role of the lateral reinforcement. The concrete cover was not also considered because it easily falls down at the ultimate condition, and normally it is not expected to contribute to the strength and ductility improvement.

\section{OBSERVED PARAMETERS}

The effectiveness of the confinement depends on 
such parameters previously reported as volumetric ratio of lateral reinforcement to the confined concrete, spacing of ties, section dimensions, yield strength of steel, arrangement of the lateral reinforcement, and compressive strength of concrete. Irawan and Maekawa ${ }^{4)}$ reported the confinement efficiency analytically in terms of the shape of section, amount of steel and the strength of constituent materials. These factors were regarded as being associated with the lateral stress distribution and the corresponding induced damage and plasticity.

In this study, the uniformity of the confinement stress in concrete and material nonlinearity are the points of discussion. Therefore, the ratio of lateral reinforcement spacing denoted by ' $s$ ' to the referential size of the confined concrete indicated by ' $d$ ' is a key parameter. Since above mentioned factors including the spacing are mutually coupled, the parametric study has to be very carefully performed. One factor is to be generally kept constant when the influence of the other is studied. In addition to these geometrical parameters, the following stress based parameters, which cannot be obtained in the experimental approach, were adopted in the parametric study as,

$$
\begin{aligned}
& \bar{\sigma}_{c}=\bar{\sigma}_{c}(z)=\frac{1}{A_{c}} \int_{A_{c}} \frac{\sigma_{c, x x}+\sigma_{c, y y}}{2} d A \\
& \bar{\sigma}_{v}=\frac{1}{V_{c}} \int_{V_{c}} \frac{\sigma_{c, x x}+\sigma_{c, y y}}{2} d V
\end{aligned}
$$

where $\sigma_{c, i j}$ is defined as the concrete stress tensor of two dimension with respect to [ij], $A_{c}$ and $H$ are the cross sectional area perpendicular to the $Z$-axis (See Fig.1) and the height of the member, respectively. $V_{c}$ is the volume of core concrete being equal to $A_{c} H$. The stress $\bar{\sigma}_{c}$ is the sectional averaging of the lateral mean stress of concrete which is supposed to be the confinement degree by the lateral steel ${ }^{4)}$. For discrete arrangement of reinforcement, not the casing, $\bar{\sigma}_{c}$ is not uniform with respect to the member axis- $Z$. The volumetric averaging of the lateral mean stress is $\bar{\sigma}_{v}$ which expresses the entire confinement supplied by the whole lateral steel. According to the mathematical compatibility, we have,

$$
\bar{\sigma}_{v}=\frac{1}{H} \int_{H} \bar{\sigma}_{c}(z) d z
$$

According to the equilibrium between concrete and lateral steel ${ }^{4}$, we have,

$$
\bar{\sigma}_{v}=-\frac{1}{2 V_{c}} \int_{V_{s}} \sigma_{s} d V
$$

where $\sigma_{s}$ and $V_{s}$ are axial steel stress and volume of steel. Then, if the steel stress at any location would be equal to the yield strength as $f_{y}$, we have the simple evaluation in using the volumetric ratio $\rho_{s}$ of steel to the core concrete as,

$$
\bar{\sigma}_{v}=-\frac{1}{2} \rho_{s} f_{y}
$$

To deduce the effect of longitudinal arrangement of lateral ties associated with the non-uniform confinement, the potential $\rho_{s} f_{y} / 2$ of lateral confinement is kept constant for the purpose of discussing the spacing of lateral ties. The cross section of each tie was varied depending on the distance between ties so that the potential lateral stress denoted by Eq.(6) would be constant. This procedure can be performed, since the contribution of flexural stiffness of ties was not taken into account as mentioned before. Therefore, there is no coupling effect of axial and flexural stiffnesses from lateral ties to the potential lateral confinement. If only the spacing would be changed and the size of the steel section be constant, the volumetric ratio of steel, which is related to the confinement magnitude, subsequently varies too. This parametric arrangement does not make any sense for the purpose of evaluating the efficiency of confinement. After this section, the compression is defined positive unless any apecial note would be given.

\section{LATERAL HOOP FOR CIRCULAR SECTION}

For the circular section with continuous encasing, because of the perfect uniformity of stress distribution and confinement actions, not depending on the amount of the steel and the strength, the concrete of any strength always has the capability to induce steel encasing to be yielded when the core concrete reaches the peak strength ${ }^{4}$. It means from Eq.(6) that the laterally induced concrete stress in $X Y$ plane in Fig. 1 always reaches the full capacity denoted by $\rho_{s} f_{y} / 2$ which represents the volumetric lateral averaged stress in the case of yielding of the entire steel.

However, when we have the discrete lateral hoops, the lateral confinement in concrete is not uniform along the column axis. Hereafter, let $s / d$ denote the bar spacing to the sectional size ratio. For circular sections, the diameter is assigned the referential size ' $d$ ' of the section, and for the square, the span length of the square. Fig.3 shows the sectional averaged lateral stress computed along the axis of columns with different reinforcing bar spacings when the $R C$ columns reach the ultimate capacity. Since the section at the position of lateral tie locally undergoes the greatest lateral confinement, it exhibits the maximum $\bar{\sigma}_{c, \text { max }}$ of the sectional averaged confinement stress $\bar{\sigma}_{c}(z)$. On the contrary, the section in between lateral ties undergoes the minimum confinement indicated by $\bar{\sigma}_{c, \min }$. The average of the sectional confinement 


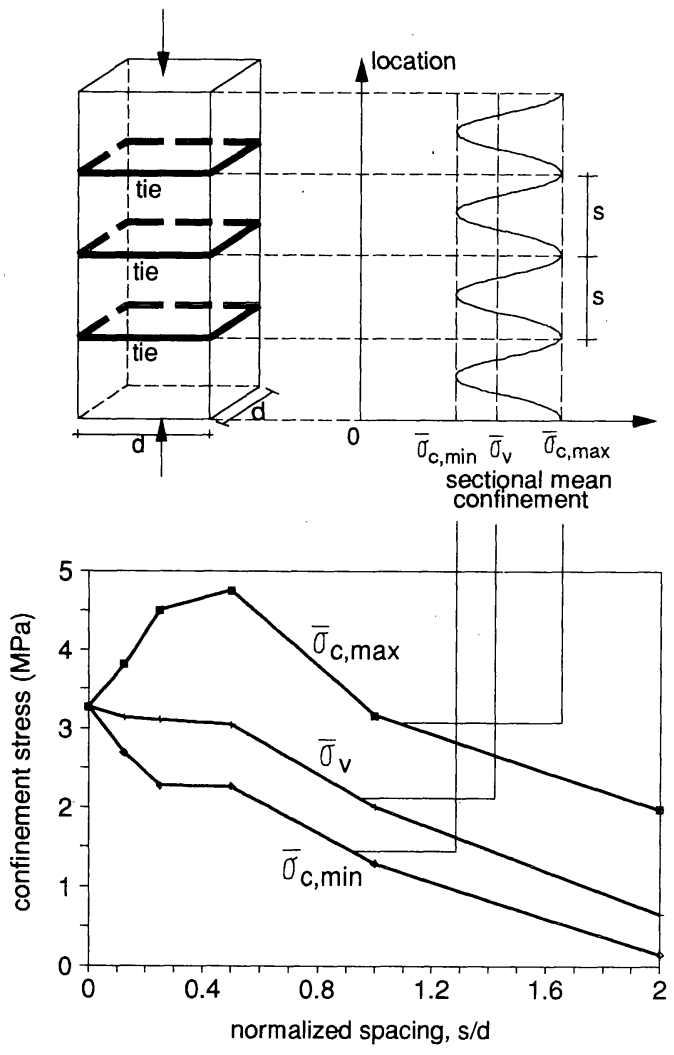

Fig.3 Sectional Averaged Lateral Confinement

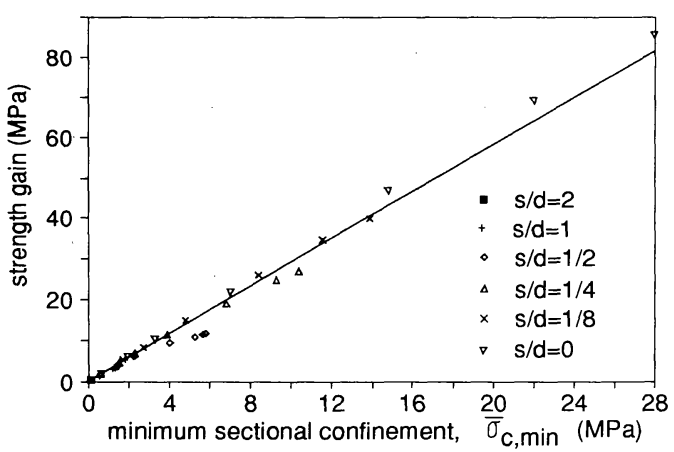

Fig.4 Relationship between Strength Gain and Minimum Sectional Confinement

with respect to the axial direction of columns coincides with $\bar{\sigma}_{v}$ in accordance with Eq.(4).

Even though the different spacing would be assigned, the value of $\rho_{s} f_{y} / 2$ was kept constant. This means that the induced lateral confinement becomes equal if the entire steel yields. The smaller spacing gves rise to the smaller deviation from the mean value of $\bar{\sigma}_{c}$ which is mathematically equal to $\bar{\sigma}_{v}$ (See Fig.3). Here, the value of $\bar{\sigma}_{v}$ is computed close to $\rho_{s} f_{y} / 2$. It means that the entire steel hoop reaches the plasticity. The capacity of the confined
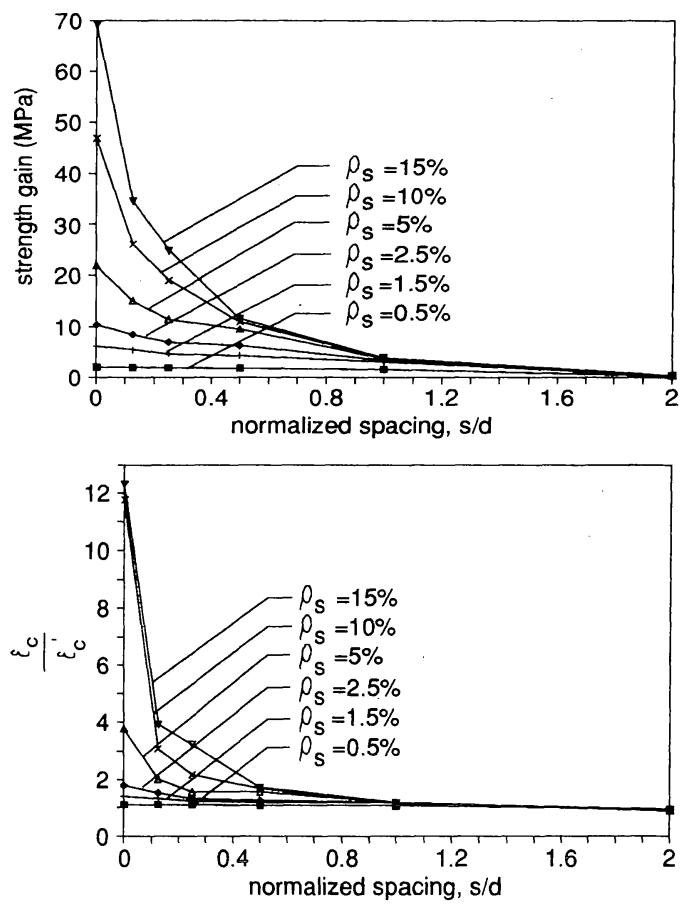

Fig.5 Effect of Spacing on Strength Gain and Ductility of Circular Section

circular concrete is governed by the weakest section having the minimum value of $\bar{\sigma}_{c}$ between adjacent ties.

With the increase of the spacing, the minimum value of $\bar{\sigma}_{c}$ between ties deviates from the mean value defined as $\bar{\sigma}_{v}$ where $\bar{\sigma}_{v}\left(=\rho_{s} f_{y} / 2\right)$ is kept constant since the same volume of steel was arranged and the whole steel also yields. However, the larger distance between adjacent hoop ties is found to lose the capability to induce the yielding to the entire steel. As shown in Fig.3, the value of $\bar{\sigma}_{v}$ gets reduced even though the value of $\rho_{s} f_{y} / 2$ intentionally remained unchanged. The minimum lateral confinement at the critical section between adjacent ties decreases with the increase of spacing. This is owing to the less lateral stresses arising in steel as well as the far location from the tie. The strength gain, which is defined as the increment of the ultimate capacity of confined concrete in comparison with uniaxial condition, is supposed to be governed by the minimum sectional averaging of lateral stress $\bar{\sigma}_{c, \min }$ at a critical section between ties. A relation of the strength gain and $\bar{\sigma}_{c, \text { min }}$ looks linear as shown in Fig.4. By combining Fig. 3 and Fig.4, we have the relationship between the strength gain and the spacing of hoops as shown in Fig.5.

The effect of spacing on the strength gain and ductility is associated with the amount of steel as 


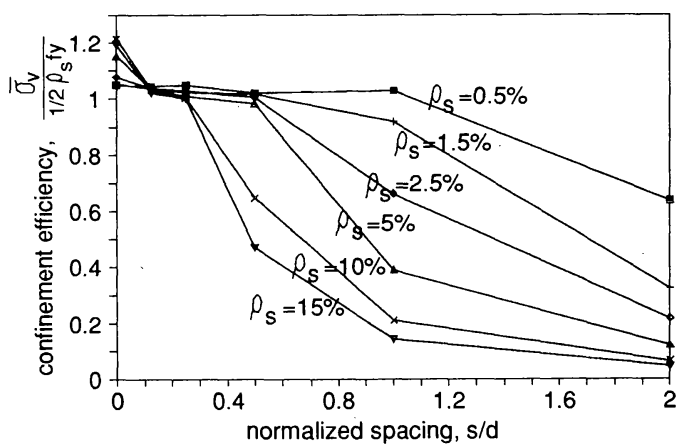

Fig.6 Effect of Spacing on Confinement Efficiency of Circular Section

shown in Fig.5. The steel volumetric ratio ranges from $0.5 \%$ to $15 \%$. The value of $15 \%$ is regarded as the extreme one which is however advisable for comprehending overall behavior and tendency on the strength gain. The peak strain at the ultimate $\left(\varepsilon_{c}\right)$ normalized by the one for unconfined concrete $\left(\varepsilon_{c}^{\prime}\right)$ is taken to represent the ductility. Confinement effectiveness of lateral steel, which is obtained by comparing the volumetric averaged confinement $\bar{\sigma}_{v}$ actually induced with the potential lateral stress $\rho_{s} f_{y} / 2$, can be seen in Fig.6. If $\bar{\sigma}_{v}$ is less than $\rho_{s} f_{y} / 2$, the lateral steel still remains elastic even though the confined concrete reaches its capacity. It means that the level of confinement can be supplied by steel which is not fully achieved.

When we place reinforcement less than $1.5 \%$ of $\rho_{s}$ by volume ratio and less than 1.0 of $s / d$ by the spacing to diameter ratio, the volumetric averaged confinement gets closely unity. Thus, the concrete with the compressive strength of $25 \mathrm{MPa}$ can induce the plasticity in steel within the condition stated above. On the contrary, if the greater deal of steel would be discretely placed (eg. $15 \%$ of $\rho_{s}$ ), the smaller spacing of hoops (eg. $s / d<0.3$ ) has to be specified in order to induce the entire plasticity in steel. But, regardless of the amount of steel, the lateral steel undergoes the plasticity when the spacing will converge to zero, that is, continuous casing $^{4}$. To avoid the instability in the calculation, the elasto-plastic model with strain hardening immediately after the yielding was applied for lateral steel (Fig.2). As a result of this, after it yields the lateral steel stress can still keep increasing. Therefore, the confinement efficiency which is based on $\rho_{s} f_{y} / 2$ can be slightly greater than 1.0 as appears in Fig.6. The confinement efficiency more than 1.0 should be interpreted as full utilization of lateral steel.

\section{HOOP AND TIE OF SQUARE SECTION}

Two types of lateral reinforcement were considered, square section with and without intermediate cross ties, where the stress distribution and confinement actions are not uniform in space. The cross-section of these shapes can be seen in Fig.1. The effect of the shape, especially the circular and square section of the steel encased core concrete, has already been discussed in the previous paper ${ }^{4}$. It was analytically examined that the square lateral encasing does not undergo the plastic yielding provided the larger amount of steel or the relatively lower strength of concrete. In other words, concrete fails prior to the yield of square casing. This is not the case of circular encasing ${ }^{4}$.

It was reported that in general, the cross tie with the square hoop gives rise to the higher strength gain and ductility than those of the lateral steel without cross ties. Fig.7 illustrates the spatial distribution of the local damage indicated by the non-dimensional variable $K$ in Eq.(1) within the critical section in both types of bar arrangement (See Fig.1). At the ultimate capacity, the sectional averaged lateral stresses $\bar{\sigma}_{c}$ are $1.33 \mathrm{MPa}$ and 0.96 $\mathrm{MPa}$ in square hoop with and without intermediate cross ties, respectively. In both cases the steel is still in elastic zone. It is obvious that the intermediate cross tie enhances the confinement effectiveness. It can be seen from Fig. 7 that the presence of the cross tie creates different damage distribution with slightly higher value of $K$ from the case of square section without cross ties.

Relations of the strength gain and the ductility with the spacing of lateral ties are shown in Fig.8. The efficiency of lateral confinement is seen in Fig.9. This value which indicates $\bar{\sigma}_{v}$ induced by the steel stress in terms of $\rho_{s} f_{y} / 2$ is useful for clarifying the nonlinearity condition of steel at the ultimate capacity of columns. In general, the sensitivity of the spacing to the strength gain depends on the amount of the lateral steel similar to the case of the circular section. As for square columns, there exists the upper limit of the strength gain of confined concrete even if the volume of lateral ties would be amplified so much (See Fig.8). As shown in Fig.9, the zero spacing as an extreme case does not always exhibit the full plasticity but the elastic zone remains in steel if the greater deal of lateral steel is placed. It can be clarified that the reduced confinement effectiveness by the greater deal of lateral steel offsets the benefit granted by the larger volume of lateral steel. This is also rooted in the geometrical aspect of sectional shapes already discussed analytically by the authors ${ }^{4)}$ and ex- 

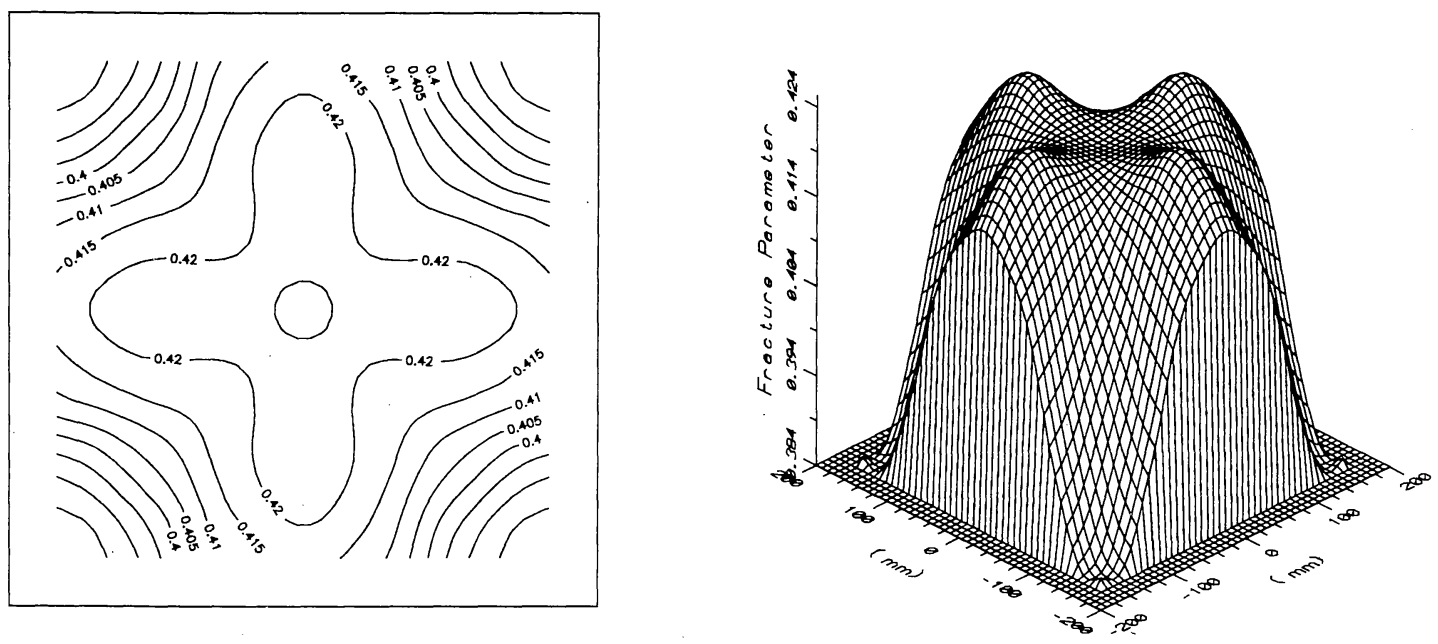

(a) Square Section without Intermediate Cross Ties
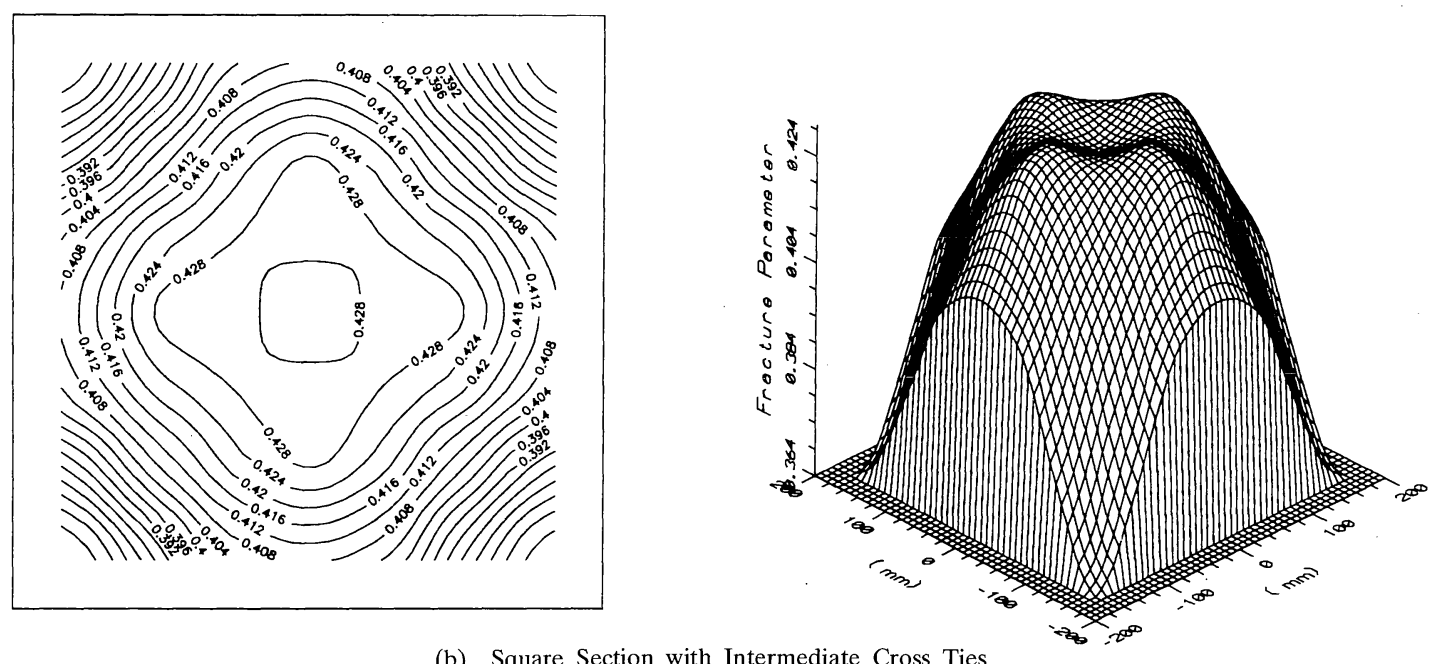

(b) Square Section with Intermediate Cross Ties

Fig.7 Spatial Distribution of Damage within the Critical Section

perimentally by others ${ }^{6,21)}$.

The above mentioned sensitivity of the volume ratio of steel could be fairly pointed out from Fig.10. In the case that the steel is still in the elastic zone at the peak of stress-strain diagram (confinement efficiency less than 1.0), almost no increment of the strength were observed. In the elastic zone, the increment of the volumetric ratio only affects the mean steel stress being reduced in the lateral reinforcement without increasing the strength of confined concrete totally. It is because the level of confinement induced by the whole lateral reinforcement are not improved. The internal damage in the concrete makes the confined concrete itself lose the capability to expand and to force the lateral reinforcement to produce more confinement actions. In other words, the use of the excessive lateral reinforcement more than necessary does not evolve the performance of the confined concrete efficiently. Through the parametric studies by finite element method, it was found that the spacing of ties affects the whole confinement stress level represented by $\bar{\sigma}_{v}$ as well as the distribution of the local lateral confinement stress denoted by $\bar{\sigma}_{c}$.

\section{COMPARISON WITH EXISTING DESIGN EQUATIONS}

As mentioned earlier, considerable works have been done with regard to the strength and deformation of the confined concrete. Among the previous researches on rectangular sections, the influence of the volumetric ratio of lateral reinforcement obtained the most attention. Burdette et al. ${ }^{3)}$ observed that only this parameter and the yield stress of steel reinforcement influence the performance of the confined concrete core. Iyengar et al. ${ }^{5}$ 

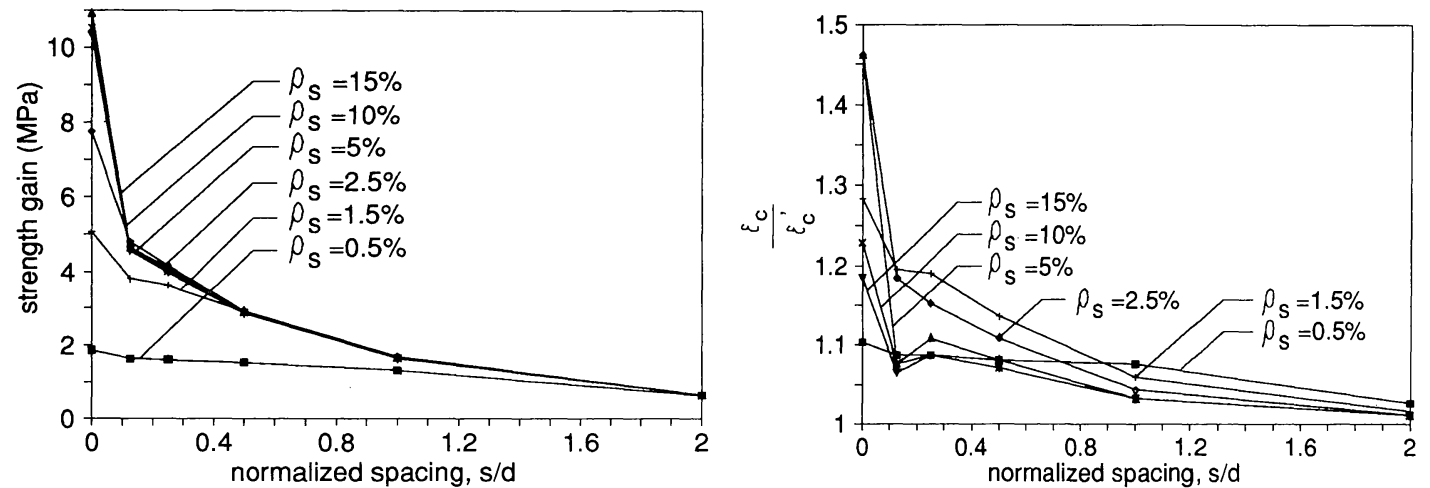

(a) Square Section without Intermediate Cross Ties
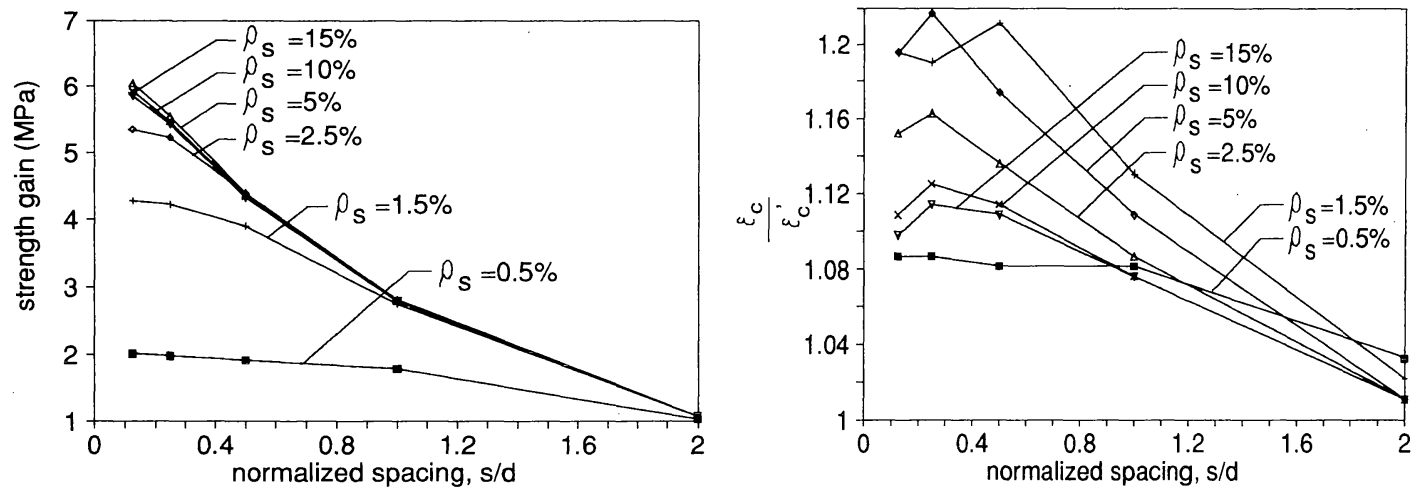

(b) Square Section with Intermediate Cross Ties

Fig.8 Effect of Spacing on Strength Gain and Ductility of Square Section

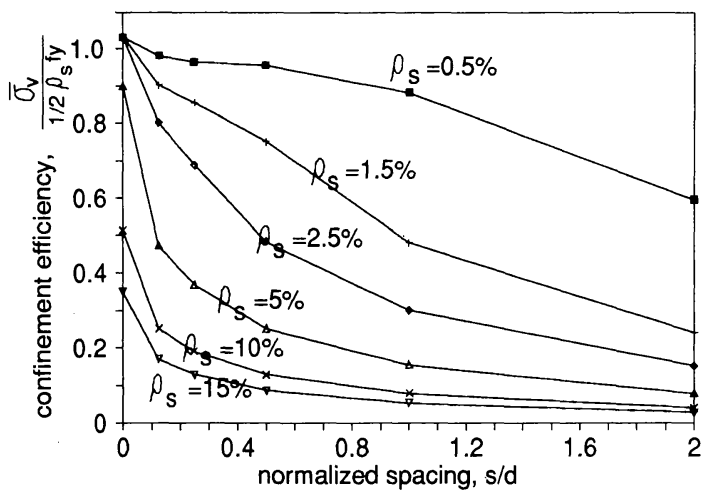

(a) Square Section without Intermediate Cross Ties

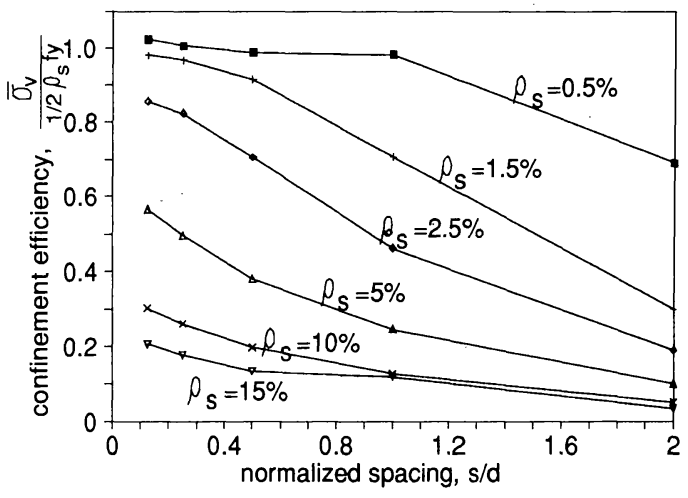

(b) Square Section with Intermeediate Cross Ties

Fig.9 Effect of Spacing on Confinement Efficiency of Square Section

included the compressive cylinder strength of concrete in their proposal for predicting the strength gain of the confined concrete with rectangular shapes. The influence of spacing ratio appeared in the proposal by Sargin ${ }^{14)}$, which was agreed by Vallenas et al. ${ }^{22)}$. At last, Sheikh and Uzumeri $^{18)}$ included the effect of lateral reinforcement configuration to predict the performance of confined concrete.
Results by the finite element analysis are presented with the existing design equations which empirically derived from the previous researches (See Fig.11-13). Two parameters, which are the lateral reinforcement ratio and the spacing to sectional size ratio denoted by $s / d$, are varied systematically. It has to be stated that each empirical equation might be invalid in some range conducted in the parametric study no matter what 

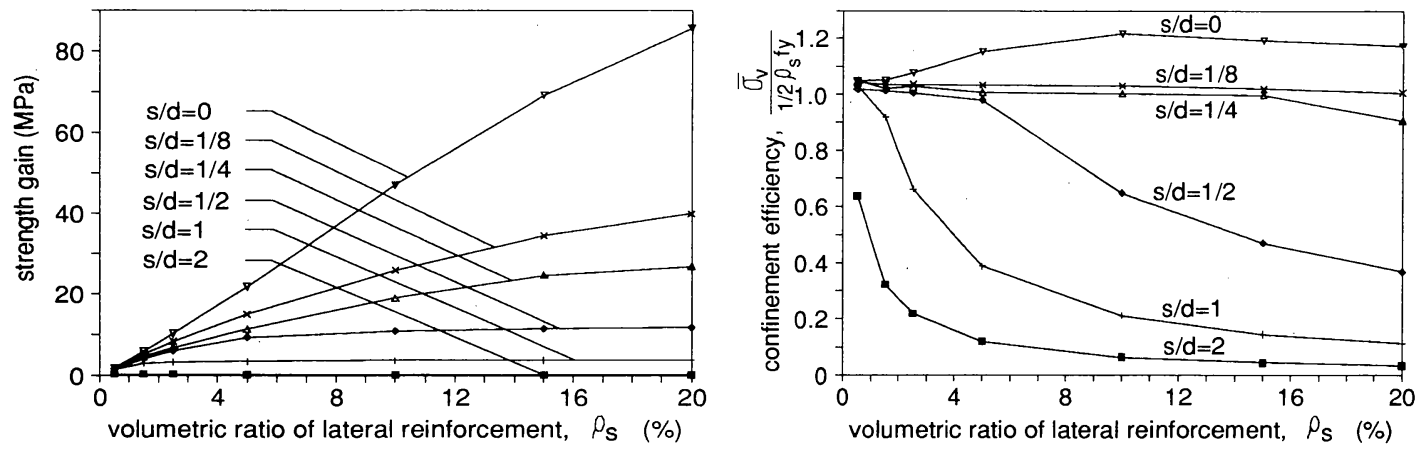

(a) Circular Section
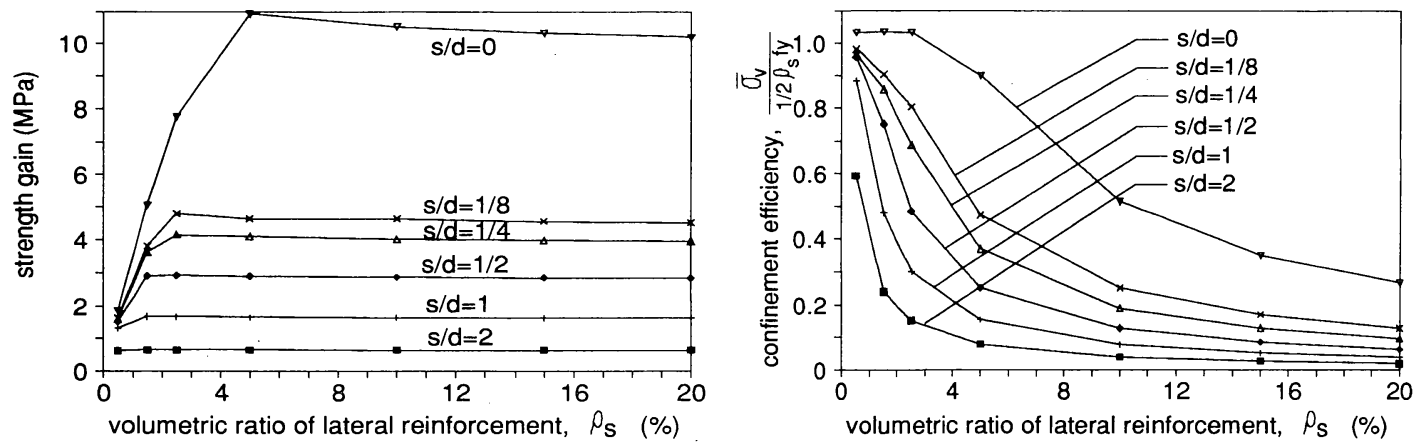

(b) Square Section without Intermediate Cross Ties
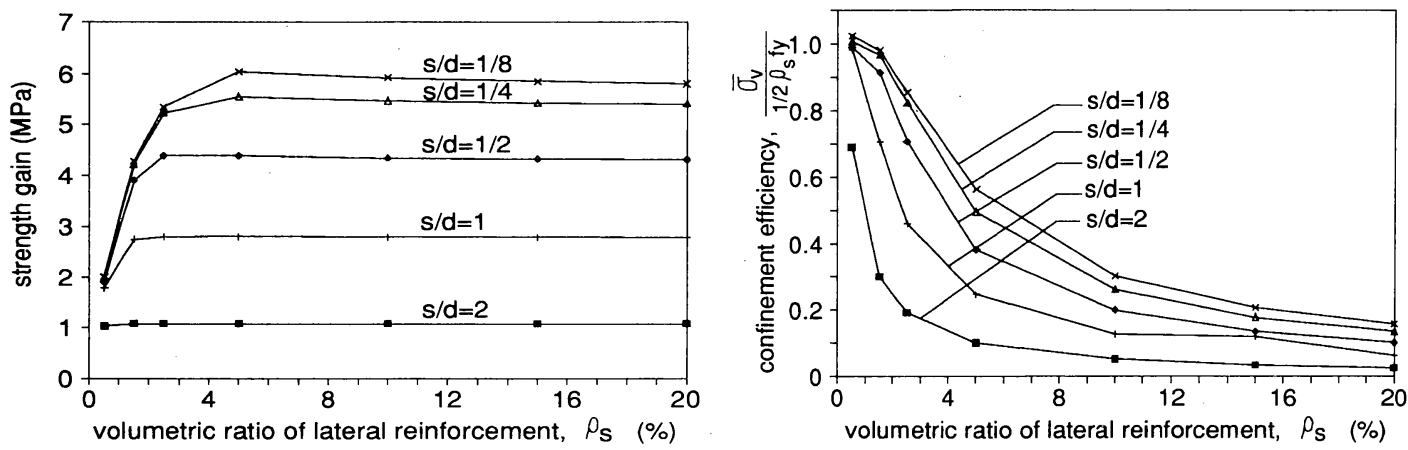

(c) Square Section with Intermediate Cross Ties

Fig.10 Relationship between Amount of Lateral Reinforcement and Strength Gain and Confinement Efficiency

applicability would be specified. Observed is the discrepancy among the empirical equations whatever experimental database is assumed. As far as the smaller spacing of circular hoop ties is concerned, the predictions by the authors' analyses seem close to the proposal by Mander and Iyengar. As for the range of larger spacing, however, the strength gain computed by the constitutive model appears to be close to the prediction by Shah et al. ${ }^{15)}$ for circular sections.

Fig.12 shows the strength gain of square sections without intermediate cross ties. The analytical results are comparatively close to the prediction by
Sheikh and Uzumeri ${ }^{14)}$ except for very small spacing less than 0.1 by $s / d$. It is reminded that these design equations are not derived from circular casing. The large amount of steel was analytically proved to be inefficient on the confinement (See Chapter 5 or reference $\left.{ }^{4)}\right)$. The models except for Sheikh and Uzumeri's one give higher predictions because the sensitivity of the volume ratio on the strength gain is assumed linear. Sheikh and Uzumeri's model alone assumes the square root sensitivity of the volume ratio.

According to the analytical and experimental investigation, the volumetric ratio should not be 

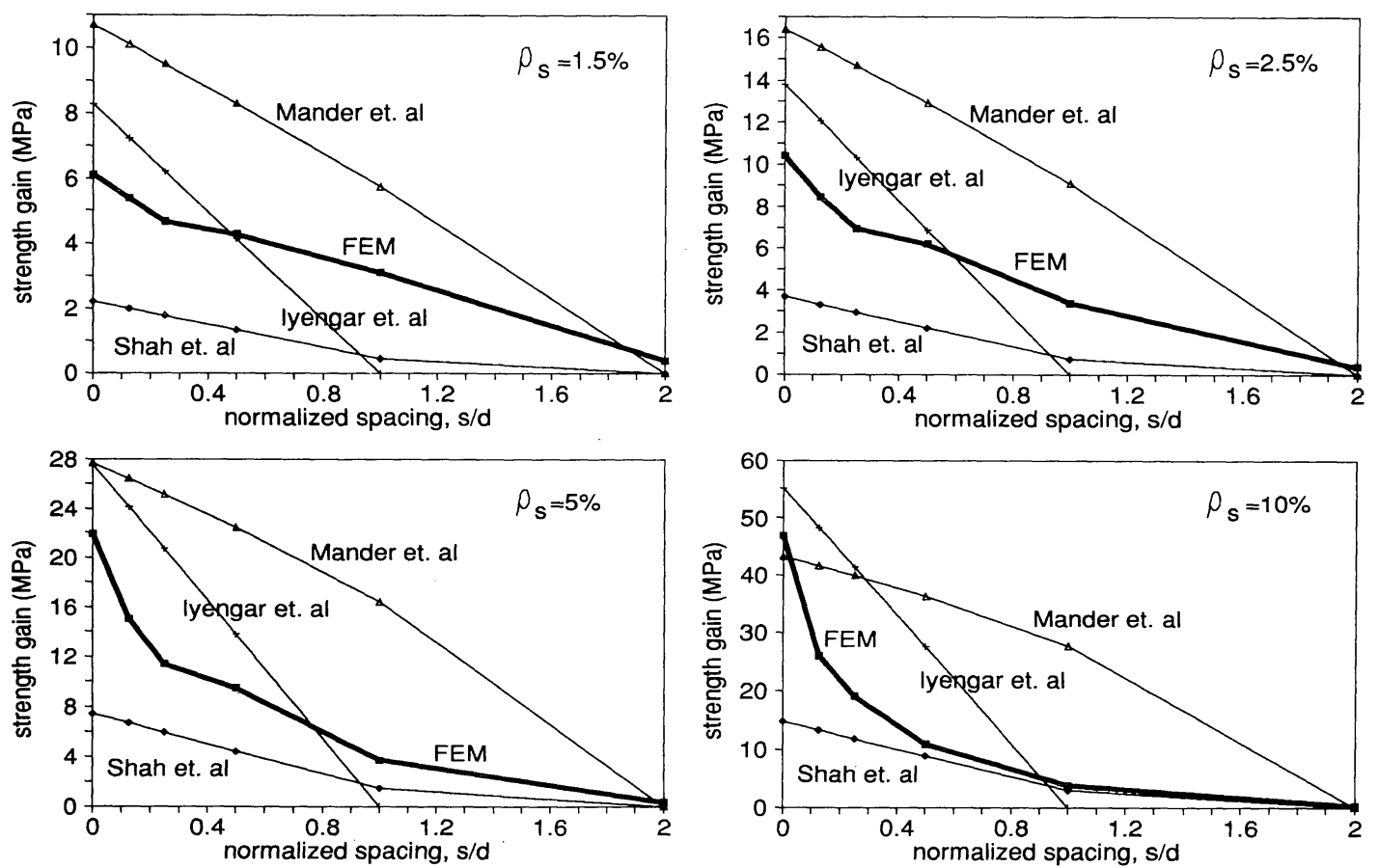

Fig.11 Strength Gain of Confined Concrete Columns of Circular Section
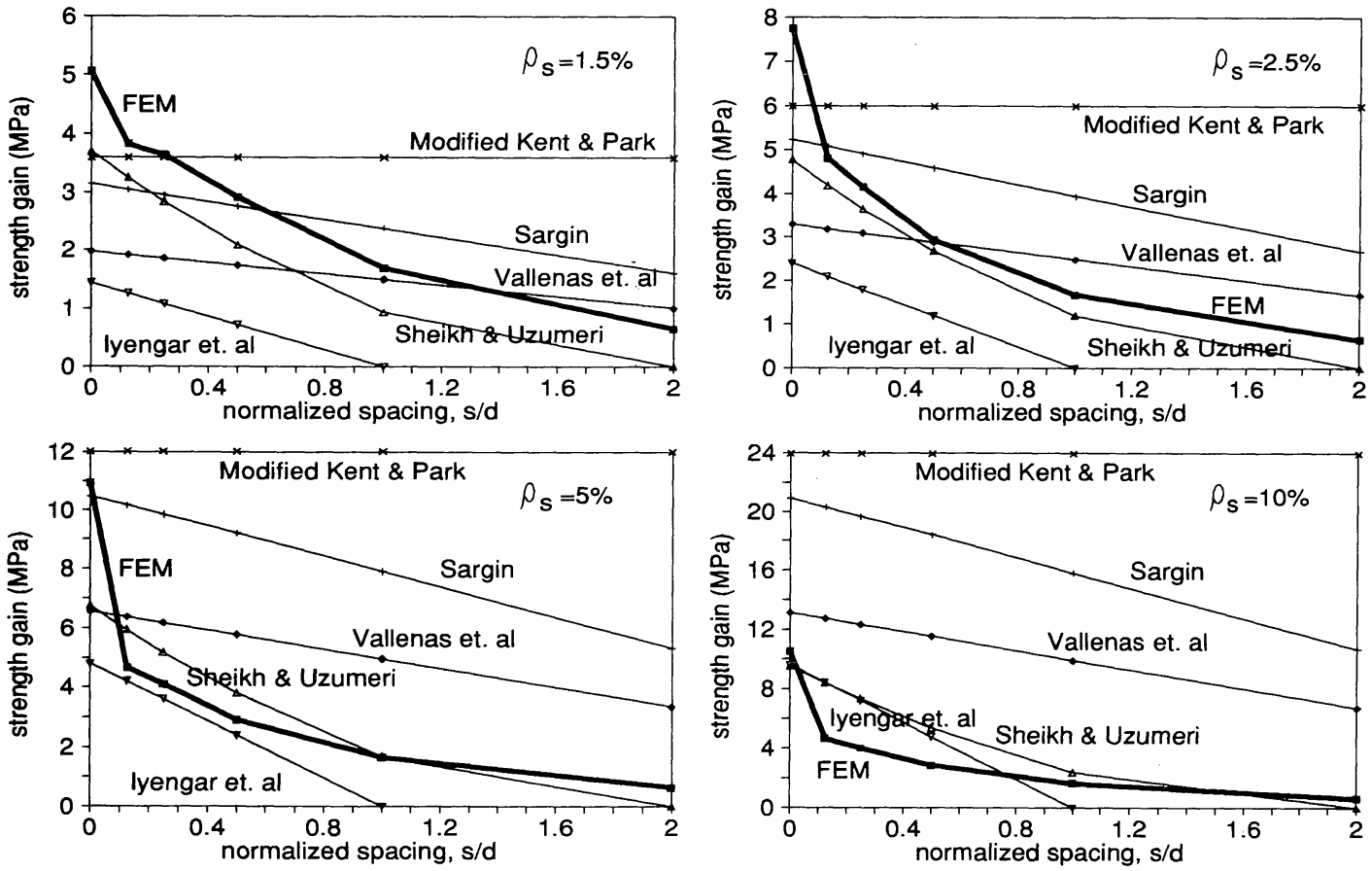

Fig.12 Strength Gain of Confined Concrete Columns of Square Section without Intermediate Cross Ties 



Fig.13 Strength Gain of Confined Concrete Columns of Square Section with Intermediate Cross Ties

regarded as being proportional to the induced sectional confinement due to the presence of remaining elasticity in steel, which means the inefficient usage of the lateral reinforcement. The accuracy of the analysis was verified in the case of steel lateral encasing ${ }^{4}$.

The intermediate cross ties change the stress distribution over a cross section. Contrary to the simple square hoop, analytically obtained compressive capacity of cross tied members is found to be smaller than the one predicted by Sheikh and Uzumeri (See Fig.13). Other models are avoided in the discussion since the presence of intermediate cross tie cannot be taken into account. The tendency is that the smaller spacing shows the bigger discrepancy between the predictions of the authors and those of Sheikh and Uzumeri. Actually, in the analysis, there exists no greater difference between the strength gain of the cross tie reinforcement and that of no tie. In reality, design equations including Sheikh and Uzumeri's were derived from the loading experiments having the longitudinal reinforcing bars which can serve to confine the lateral expansion of core concrete concerned as well as to carry some of the axial loads. The cross tie arrangement implies the effective lateral confinement by longitudinal reinforcement.

The finite element analysis proposed in this paper does not take into account the presence of longitudinal reinforcement as lateral confinement agent. In other words, it can be understood that the design equations do not separate the confinement efficiency into those originating in the lateral and longitudinal reinforcement. This will be the topic to be analytically clarified in the next stage of investigation as well as the effect of flexural rigidity of the discretely arranged bars.

\section{CONCLUSIONS}

The compressive load bearing capacity of laterally reinforced concrete results from the complex stress distribution in three dimensional space. To enlighten the confinement efficiency by lateral steel, the three dimensional stress field is analyzed with the aid of FEM and the elasto-plastic and fracture models for concrete. The sectional averaged lateral stress and the volumetric averaging were quantitatively evaluated. These stress based information cannot be obtained from experiments. The followings are analytically investigated.

(1) For circular columns with discrete lateral hoops, the larger spacing between adjacent hoops results in the less lateral confinement to the critical section of core concrete. It is computationally shown that the lateral confinement stress which is transferred along an axis gets reduced through the longer distance. In addition, the absolute hoop stress itself is reduced with the greater spacing. The 
spacing has the duplicated effects on the whole confinement efficiency.

(2) For square columns with or without cross ties, the spacing has the similar influence on the confinement to the core concrete. It is analytically pointed out that the square hoop loses the confinement efficiency when larger spacing and/or greater amount of steel would be assumed.

(3) The presence of cross tie is taken into account in analysis. The tie improves the confinement efficiency since the intermediate steel reinforcement makes the internal stress and damage distribution smoother even when the same amount of steel would be allocated in concrete. The mean value of the sectional non-uniform damage, which is indicated by the fracture parameter, is proved to be greater than the one of the lateral square ties without any cross reinforcement. These comparison is made under the same amount of steel which means the same volumetric averaging of lateral confinement stress, which can be attained provided the entire plasticity of the lateral steel reinforcement.

(4) The analytical results are compared with the prediction by empirical formula oriented to the design for confined members. The computed strength gain is examined to be close to some empirical equations. Through the verification, the sensitivity of each factor to the strength gain is studied for the new proposal of design equations having the mechanical background in future.

ACKNOWLEDGMENT : The authors are grateful to Prof. H. Okamura, the University of Tokyo for his valuable advices. The first author expresses his gratitude to German Academic Exchange Service (DAAD), Federal Republic of Germany for the granted scholarship in Asian Institute of Technology (AIT), Thailand. The financial support was granted to the second author by Japan International Cooperation Agency when he served in AIT and by the Japanese Government in line with Grant-in-Aid for scientific research No. 04555114 .

\section{REFERENCES}

1) Ahmad, S.H., and Shah, S.P. : Complete Triaxial StressStrain Curves for Concrete, Journal of the Structural Division, ASCE, 108(4), 728-742, 1982.

2) Ahmad, S.H., and Shah, S.P. : Stress-Strain Curves of Concrete Confined by Spiral Reinforcement, American Concrete Institute Journal, 79(46), 484-490, 1982.

3) Burdette, E.G., and Hilsdorf H.K. : Behavior of Laterally Reinforced Concrete Columns, Journal of the Structural Division, ASCE, 97(2), 587-602, 1971.

4) Irawan, P., and Maekawa,K. : Strength and Damage
Analysis of Core Concrete Confined by Steel Casing, J. Materials, Conc. Struct., Pavements, JSCE, 472/V-20, 97-106, 1993.

5) Iyengar, K.T.S.R., Desayi, P., and Reddy, K.N. : Stress Strain Characteristics of Concrete Confined in Steel Binders, Magazine of Concrete Research (London), 22(72), 173-184, 1970.

6) Kato, D. : Ductility of Reinforced Concrete Columns with Different Reinforcement Details, Proceedings of JCI Symposium on Design of Reinforcement and Ductility of Concrete Structures, JCI, JCI-C 20, 131-138, 1990.

7) Kent, D.C., and Park, R. : Flexural Members with Confined Concrete, Journal of the Structural Division, ASCE, 97(7), 1969-1990, 1971.

8) Mander, J.B., Priestley, M.J.N., and Park, R. : Theoretical Stress-Strain Model for Confined Concrete, Journal of the Structural Division, ASCE, 114(8), 1804-1826, 1988.

9) Maekawa, K., and Okamura, H. : The Deformational Behavior and Constitutive Equations for Concrete Using Elasto-Plastic and Fracture Model, Journal of the Faculty of Engineering, The University of Tokyo (B), 37(2), 253-328, 1983.

10) Maekawa, K., Takemura, J., Irawan, P., and Irie, M. : Continuum Fracture in Concrete Nonlinearity under Triaxial Confinement, Proceedings of JSCE, 460/V-18, 113-122, 1993.

11) Maekawa, K., Takemura, J., Irawan, P., and Irie, M. : Plasticity in Concrete Nonlinearity under Triaxial Confinement, Proceedings of JSCE, 460/V-18, 123-130, 1993.

12) Maekawa, K., Takemura, J., Irawan, P., and Irie, M. : Triaxial Elasto-Plastic and Fracture Model for Concrete, Proceedings of JSCE, 460/V-18, 131-138, 1993.

13) Okamura, H., and Maekawa, K. : Nonlinear Analysis and Constitutive Models of Reinforced Concrete, Giho-do Syuppan Co. Ltd., Tokyo, Japan, 1991.

14) Sargin, M. : Stress-Strain Relationships for Concrete and the Analysis of Structural Concrete Sections, Study No.4, Solid Mechanics Division, University of Waterloo, 1971.

15) Shah, S.P., Fafitis, A., and Arnold, R. : Cyclic Loading of Spirally Reinforced Concrete, Journal of the Structural Division, ASCE, 109(7), 1695-1710, 1983.

16) Sheikh, S.A. : A Comparative Study of Confinement Models, American Concrete Institute Journal, 79(30), 296-306, 1982.

17) Sheikh, S.A., and Uzumeri, S.M. : Strength and Ductility of Tied Concrete Columns, Journal of the Structural Division, ASCE, 106(5), 1079-1102, 1980.

18) Sheikh, S.A., and Uzumeri, S.M. : Analytical Model for Concrete Confinement in Tied Columns, Journal of the Structural Division, ASCE, 108(12), 2703-2722, 1982.

19) Soliman, M.T.M., and Yu, C.W. : The Flexural StressStrain Relationship of Concrete Confined by Rectangular Transverse Reinforcement, Magazine of Concrete Research (London), 19(61), 223-238, 1967.

20) Song, C., and Maekawa, K. : Dynamic Nonlinear Finite Element Analysis of Reinforced Concrete, Journal of the 
Faculty of Engineering, The University of Tokyo (B), .41(1), 73-158, 1991.

21) Suzuki, K., Nakatsuka, T. and Kishimoto, I. : Analytical Investigation on Confining Reinforcement Required to Obtain Flexural Ductility of RC Columns, Proceedings of JCI Symposium on Design of Reinforcement and Ductility of Concrete Structures, JCI, JCI-C 20, 139-146, 1990.
22) Vallenas, J., Bertero, V.V., and Popov, E.P. : Concrete Confined by Rectangular Hoops and Subjected to Axial Loads, Report No. UCB/EERC-77/13, Earthquake Engineering Research Centre, University of California, Berkeley, 1977.

(Received October 16, 1991)

鉄筋により横拘束されたコンクリートの強度・変形に関する 3 次元解析

Paulus IRAWAN・前川宏一

分散配置された横補強鉄筋で拘束されるコンクリートの中心軸圧縮挙動を, 弾塑性破 壊構成則を用いた 3 次元有限要素解析を用いて解析し, あわせて既往の強度実験式との 比較を行った．横補強鉄筋の間隔は，コンクリートに発生する 3 次元応力場と材料損傷 度の均一性を変化させるとともに, 鋼材による拘束コンクリートへの拘束力自体にも大 きく影響を及ぼすこと，その機構を塑性と破壊の観点から解析的に示した. 